\title{
Role of ING Family Tumor Suppressors in Breast Cancer
}

\author{
Mehmet Gunduz ${ }^{1}$, Esra Gunduz ${ }^{2}$, Mikdat Bozer ${ }^{3}$ and Ramazan Yigitoglu ${ }^{4}$ \\ ${ }^{1}$ Departments of Medical Genetics and Otolaryngology, \\ ${ }^{2}$ Department of Medical Genetics, \\ ${ }^{3}$ Department of General Surgery-Surgical Oncology Section, \\ ${ }^{4}$ Department of Medical Biochemistry, \\ School of Medicine, Fatih University, Ankara, \\ Turkey
}

\section{Introduction}

Today cancer is one of the leading diseases, which treat human life and enormous efforts are being done for its eradication. Currently many cancer types including breast cancer are treated by extensive surgery as well as chemo-radiotherapy. These treatment modalities usually present extensive damage to the patient both anatomically, physiologically and psychologically. In addition, chemo-radiotherapy shows extreme side effects of the other system in the body and their efficiencies are quite limited especially in disseminated metastatic cases. Recent developments and progress in human genome technology provided us to develop novel therapeutic methods. This progress also provided novel biomarkers, which early diagnose the cancer and predict the sensitivity of the current chemo-radiation therapies.

Tight control by various regulatory mechanisms is applied on cell proliferation and growth in normal cells. However, certain genetic and epigenetic alterations permit the normal cells to avoid these mechanisms allowing indefinite cellular activities. Cancer is basically a genetic disease. The collection of genetic and epigenetic alterations of multiple genes and chromosomes lead to the development of cancer. In this regard, two major groups of tumorassociated genes, oncogenes and tumor suppressor genes (TSGs), have been implicated in the carcinogenic process (Figure 1).

TSGs have been defined as genetic elements whose loss or mutational inactivation allows cell to display one or more phenotypes of neoplastic growth [1]. TSG protein products are known to be involved in negative regulation of the cell cycle and proliferation and induction of apoptosis by different mechanisms. Thus inactivation of TSGs is one of the crucial steps during carcinogenetic process. In this process according to Knudson two-hit hypothesis for inactivation of TSGs [2], the deletion of targeted chromosomal regions (location of TSGs) eliminates one allele, while inactivating events (mutation, deletion, or epigenetic events such as promoter hypermethylation) affect the other allele of a concerning TSG [2]. The detection of frequent loss of heterozygosity $(\mathrm{LOH})$ in a chromosomal locus is considered to be critical evidence for the localization of a TSG. 

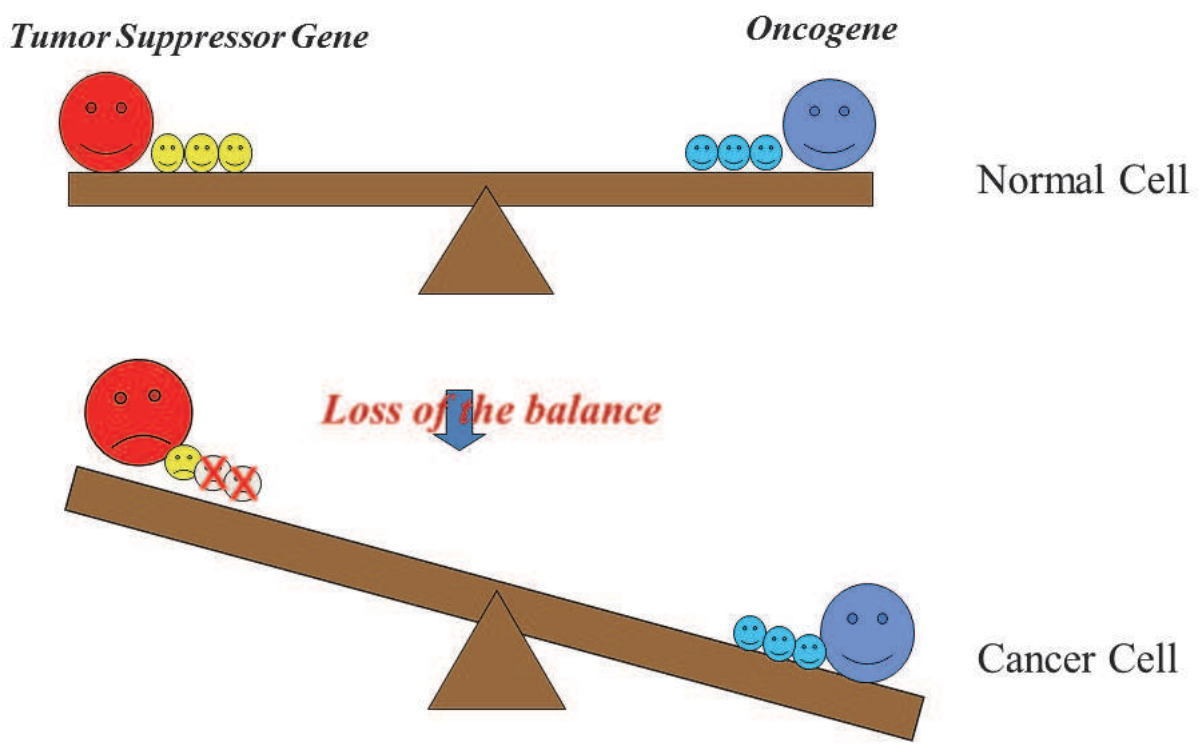

Fig. 1. Role of Oncogene and Tumor Suppressor Gene in Cancer.

Two group of genes (oncogene and tumor suppressor gene) influence on physiological cell proliferation and growth. In cancer development, balance between these two groups of genes is broken. Either oncogene activation or tumor suppressor gene inactivation promotes cancer development.

In fact many TSGs including well-known p53, RB1, p16, p21, and FHIT etc have been recently identified by using $\mathrm{LOH}$ analysis and then positional cloning. Inactivation of these classical TSGs usually occurs through deletion of one of its allele and mutation in the rest allele (Class I TSG, Knudson hypothesis). However, a novel class of TSGs with haploid insufficiency, in which one allele is lost and the remaining allele is haplo-insufficient, has been described recently, and the patients with these hemizygous TSGs in their genome are accepted as carriers for deficient allele of a TSG and they show a tumor-prone phenotype especially when challenged with carcinogens such as smoking, alcohol, x-ray, chemicals etc (Class II TSG) [3-7] (Figure 2).

The novel TSG family, inhibitor of growth (ING), belongs to the group of genes that encodes proteins containing structural motifs involved in chromatin remodeling and transcription regulation. The ING family is classified as type II tumor suppressor since its inactivation has been implicated in neoplastic growth of various tumors [8-10]. Five human ING genes (ING1-5) have been identified and among them, ING1 is the founding member and the most widely studied. ING1 was first isolated using subtractive hybridization between short segments of cDNAs from normal and a number of breast cancer cell lines [11]. These randomly fragmented cDNAs interfered with the activity of tumor suppressors by either blocking protein production through anti-sense sequences or abrogating function in a dominant-negative fashion through truncated sense fragments [11]. Acute expression of transfected constructs encoding this gene inhibited cell growth while chronic expression of 


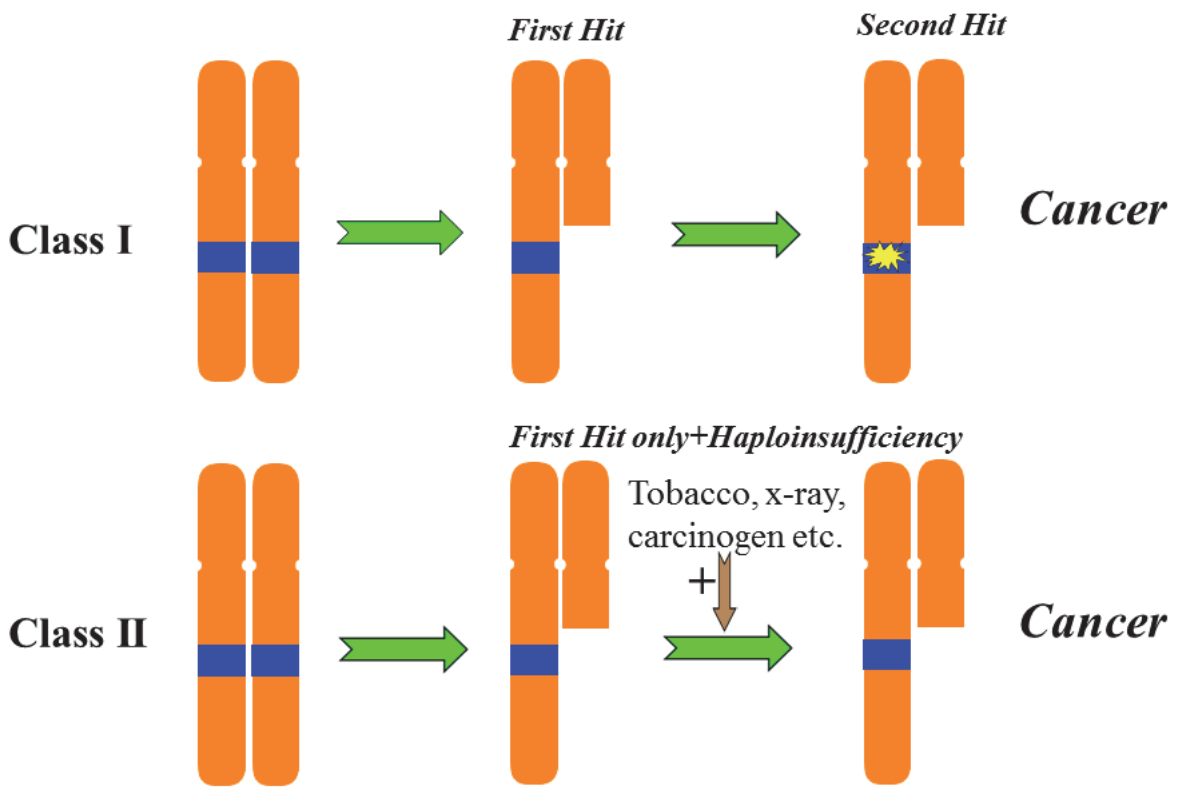

Fig. 2. Cancer Development through Inactivation of Tumor Suppressor Genes. Knudson two-hit hypothesis for inactivation of TSGs, the deletion of targeted chromosomal regions (location of TSGs) eliminates one allele, while inactivating events (mutation, deletion, or epigenetic events such as promoter hypermethylation) affect the other allele of a concerning TSG (Class I). TSG with haploid insufficiency, in which one allele is lost and the remaining hemizygous allele is not enough to provide full suppression on cellular proliferation. These patients are carrier for deficient allele of a TSG and they show a tumorprone phenotype especially when challenged with carcinogens such as smoking, alcohol, xray, chemicals etc (Class II).

antisense ING1 constructs promoted transformation of mouse breast epithelial cells and increased the frequency of focus formation with NIH3T3 cells and protected cells from apoptosis [11, 12]. Using radiation hybrid analysis, ING1 gene was mapped on human chromosome 13q33-34 [13]. The other four members have been disclosed through sequence homologies with ING1, followed by functional in-vitro and then in-vivo cancer patient tissue analysis $[9,10,14-16]$. However, recent researches demonstrated opposite findings for some of ING family members such as ING2 as a possible oncogene in specific conditions. In fact, ING2 expression was found to be increased in colorectal cancer and knock-down of ING2 suppressed cell growth and induced cell cycle arrest or apoptosis [17].

\section{Structure and function of ING family genes}

All members of ING family have distinct N-termini, which dictate the specific role of the ING members and, in certain instances, their antagonistic regulatory function $[9,10,14-16]$. Also all ING family members exhibit a highly conserved C-terminal plant homeodomain (PHD) that is commonly found in various chromatin remodeling proteins [9,10,14-22] 
(Figure 3). The PHD motif consists of about 60 amino acids and shows a C4HC3 ring structure that typically binds two Zn2+ ions [16]. Approximately 150 distinct PHD domainbearing proteins have been predicted to occur in humans [16]. PHD domains have been implicated in chromatin remodeling due to presence of their proteins as known components of larger chromatin remodeling complexes, and may function by strengthening a separate chromatin-binding activity of either the same protein or an associated protein [16]. Mutations within the PHD fingers of numerous proteins have been reported to be linked to tumorigenesis, immuno-deficiency syndromes, autoimmune syndromes, and several other genetic disorders [15, 23-26]. These mutations mainly occur at zinc-coordinating residues, suggesting that zinc ligation and hence integrity of the PHD finger fold are critical for the function of PHD finger-containing proteins [15].

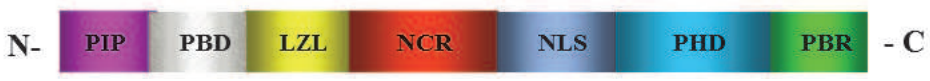

Fig. 3. Structure and Interacting Domains of ING Family Proteins.

All ING family proteins have a highly conserved plant homeodomain (PHD) finger motif, Novel Conserved Region (NCR) and Nuclear Localization Sequence (NLS). NLS directs ING to the nucleus through binding of the karyopherin/importins. NCR serves as an interacting site for lamin A as well as HAT/HDACs. The PHD finger binds to histone $\mathrm{H} 3$ and has a role in chromatin regulation. PCNA-interacting motif (PIP) and Partial Bromodomain (PBD) are specific to ING1. The PIP motif binds to PCNA and promotes ING1-mediated apoptosis. PBD domain binds SAP30 of mSin3A-HDAC1 and has a role in transcription regulation. All ING proteins except ING1 include LZL domain, which has roles in apoptosis and nucleotide excision repair of DNA. Both ING1 and ING2 include a short polybasic region called as PBR, to which PtdIns3P and PtdIns4P bind.

All ING proteins contain nuclear conserved region (NCR) domain, which was identified by sequence analyses and is the second most highly conserved domain in the ING family proteins [15]. This N-terminal region of ING1 has been reported to interact directly with lamin A, suggesting that the association with nuclear lamina is a common feature of this family [27].

All ING proteins contain a nuclear localization signal (NLS) at the carboxy terminal, and some of ING proteins have multiple NLS. Deletion of the NLS of ING1 resulted in cytoplasmic accumulation of the protein [28,29]. Translocation of ING proteins into the nucleus has been thought to be critical for their function because these molecules are nuclear proteins, and also it is clearly considered to be so by the observation of loss of nuclear ING1 staining in a number of cancers [16,30]. Deletion of the entire NLS of ING4 resulted in a protein that could no longer bind p53 in co-transfection experiments [31]. Moreover, two copies of a putative nucleolar translocation signal (NTS) were found within the NLS of ING1, and translocation of ING1 into the nucleolus following exposure to UV light was suggested to be required for ING1-associated apoptosis [16,28].

All ING proteins, except ING1, contain leucine zipper-like (LZL) domain at the N-terminus. LZL domain forms a hydrophobic patch consisting of four to five conserved leucine or isoleucine residues spanning every seven amino acids. Similar leucine distribution has also been reported for ING3 to ING5 [15,32,33]. There is few information about the function of LZL and it been has reported that the LZL domain of ING2 is required for the induction of apoptosis and NER [34]. ING2 deletion mutants lacking the LZL domain do not show 
increased apoptosis following UV exposure, suggesting that this domain is necessary for ING2-mediated apoptosis [34]. RNAi-mediated knockdown of ING2 has also been reported to abrogate the nucleotide excision repair (NER) capacity of melanoma cells [35].

Within ING family members, only ING1 includes PCNA binding domain called as PIP box in a DNA damage-inducible manner at N-terminus. This domain indicates the role of ING1 in DNA repair since PCNA has roles for DNA replication and repair. The interaction of this domain is specifically induced upon UV damage and has been thought to change PCNA activity away from DNA replication towards DNA repair [36]. Another unique domain present only in ING1b is called as PBD (partial bromodomain because of its sequence homology to bromodomains), which binds SAP30 of mSin3A-HDAC1, suggesting its role in transcriptional regulation of some genes [37].

Both ING1 and ING2 include a short polybasic region called as PBR at C-terminus. Though exact functions of this domain remain unknown, it has been reported that PtdIns3P and PtdIns4P can bind to the PBR [10,38], while PtdIns5P binds to the PHD motif of ING2 $[10,39]$.

\section{Genomic location, structure and expression of ING family genes}

Most ING family genes are ubiquitously expressed in human tissues. We characterized genomic structure of human ING1 gene, and demonstrated that the human ING1 gene contains three exons (1a, $1 \mathrm{~b}$ and 2) and two introns [8]. The gene has been mapped to chromosome 13 (13q33-34), and it has been found to encode 4 different mRNA variants. ING1 is ubiquitously expressed in various tissues [8]. The second member of the ING family, ING2 gene, has been mapped on chromosome 4 (4q35.1) and has been known to have 2 variants; ING2a and ING2b [40]. ING2 has 3 exons including ex1a, ex1b and 2 [41]. Our group identified the ING3 gene on chromosome 7 (7q31). The ING3 also encodes 2 different variants $[9,10,41,42]$. ING3 has 12 exons at its genomic location. The ING4 gene has been mapped on chromosome 12 (12q13.3) and encodes 8 variants with 8 exons $[9,10,43,44]$. The ING5 gene has been mapped on chromosome 2 (2q37.3) and encodes at least 5 different splicing variants with 8 exons $[9,10,45]$.

\section{Biological functions of ING family genes}

ING proteins are involved in regulation of various cellular processes and signaling pathways such as angiogenesis, growth regulation, senescence, apoptosis, chemosensitivity, cell cycle, cell migration and DNA repair through p53-dependent and -independent pathways. ING proteins form complexes with HAT/HDAC $[9,10,46]$. After discovery of ING family genes prototype ING1, most of the functional studies have been conducted using ING1 variants, but fewer recently increasing studies, involving other ING family members, have also identified similar roles for these ING proteins. In addition, inhibition of ING proteins has been shown to increase cell spreading as well as migration, and relieve contact inhibition.

p33ING1b physically associates with the p53 tumor suppressor protein and seems to be a critical cofactor in p53-mediated regulation of cell growth and apoptosis [9,10,46,47]. However in a separate study, p37Ing1, mouse variant of human p33ING1b, blocked cell proliferation regardless of p53 and did not affect p53-mediated cell growth arrest following DNA damage [48]. p37Ing1 in mice regulated Bax levels in a negative way and worked as a 
prosurvival molecule following DNA damage independent of p53 status, complicating the function of ING1 in mouse and human and in various other circumstances. Moreover, recent experiments have also suggested that there are p53-independent functions for the ING proteins, including regulation of the NF-kB and hypoxia inducible factor (HIF) pathways [49-52].

ING2 shows a high rate of homology with ING1 about $70 \%[9,10,30,34,53]$. Similar to other members of the ING family, ING2 is reported to have function in cooperation with p53, which is important for modulation of p53-mediated chromatin remodeling [54]. p33ING2 induces G1 phase cell cycle arrest or apoptosis in a p53-dependent manner following DNA damage [53]. ING2 has important roles in senescence, cellular response to DNA damage and DNA repair $[34,54]$. Recently ING2 was also shown to interact with members of the transforming growth factor (TGF) $-\beta$ signaling pathways enhancing transcription of target genes and cell cycle arrest [55]. However, overexpression of ING2 in colorectal cancer, burkitt lymphoma and cervical cancer and decreased expression in others such as head and neck carcinoma suggested that ING2 might have different function in various cancers $[9,10,19,41,56,57]$. Moreover, ING2 has 2 splicing variants and knockout experiments suggested oncogenic function of this gene $[40,41]$. In a recent study, a new function of ING2 was identified for the control of DNA replication and the maintenance of genome stability [58].

We identified ING3 for the first time by a homology search in human genome and showed ING3 as a candidate tumor suppressor in head and neck cancer [42]. Overexpression of p47ING3 protein resulted in a decreased population of cells in S phase, a diminished colonyforming efficiency, and induced apoptosis in RKO cells with wild type p53, but not in RKOE6 cells with inactivated p53, suggesting necessity of p53 protein for at least some of its functions [59]. Histone acetyl transferase (HAT) complexes are important regulators of gene expression and among these, the NuA4 complex, first characterized in yeast, stands out as it controls multiple key nuclear functions in eukaryotic cells such as regulation of transcription, cell-cycle progression as well as the process of DNA repair [60]. p47ING3 activates p53-transactivated promoters, including promoters of p21/waf1 [61] and ING3 has been a stable component of Tip60/NuA4 HAT complex that cooperates with p53 and blocked cell cycle by activating the p21/waf1 gene $[9,10,62,63]$. Tip60 is an important transcriptional cofactor for p53-, NF-kB- and Myc-dependent transcription activation, suggesting that ING3 might have functions for many processes such as apoptosis and metastasis suppression at the transcription level through its association with the Tip60/NuA4 complex [63]. ING3 expression significantly promoted apoptosis by activating the Fas/caspase-8 pathway, suggesting that ING3 may also be involved in the deathreceptor pathways $[9,10,15,64]$. Recently ING3 has been reported to be degraded by the ubiquitin-proteasome pathway through the SCF (Skp2) complex and interruption of ING3 degradation enhanced the tumor-suppressive function of ING3 [65].

p29ING4 was identified by Shiseki et al [66]. Overexpression of ING4 protein resulted in a diminished colony-forming efficiency, a decreased cell population in $\mathrm{S}$ phase, and the induction of apoptosis in a p53-dependent manner. p29ING4 also activated the p21/waf1 promoter, and induce p21/WAF1 expression [66].

ING4 has been proposed to regulate cell cycling and apoptosis. ING4 has been reported to inhibit angiogenesis by various studies besides its role for cellular processes common for all ING family members [67-69]. It has been demonstrated that ING4 physically interacts with p65 (RelA), a subunit of nuclear factor NF-kB, and that ING4 regulates angiogenesis through 
transcriptional repression of NF-kB-responsive genes in brain tumors [70]. ING4 functional studies suggest that this gene in addition to the common functions of the ING proteins could play a completely different role in tumorigenesis. Actually, ING4 is likely to be involved in inhibition of the cell's spreading and migration as well as tumor angiogenesis. Indeed, its loss results in loss of contact inhibition, activation of NF-kB transcriptional activity and enhanced cell migration. Thus ING4 deficiency may be a crucial step in malignant progression, especially for glioblastoma [9,10,15,16,66,71-75].

ING4 also associates with HBO1 (HAT binding to ORC1)/HAT complex $[63,76]$. It was shown that interaction between ING4 and H3K4me3 augments HBO1 acetylation activity on $\mathrm{H} 3$ tails and drives $\mathrm{H} 3$ acetylation at ING4 target promoters, which facilitates apoptosis in response to genotoxic stress and inhibits anchorage-independent cell growth, and these functions depend on ING4 interaction with H3K4me3 [77]. ING4 was recently reported to interact with tumor suppressor p53 through interaction with NLS domain and negatively regulate the cell growth with significant G2/M arrest of cell cycle in HepG2 cells through up-regulation of p53-inducible gene p21 [31,78].

Similar to ING4, ING5 was also identified by Shiseki et al [66]. Overexpression of ING5 protein also resulted in a diminished colony-forming efficiency, a decreased cell population in $S$ phase, and the induction of apoptosis in a p53-dependent manner. p28ING5 protein activated the p21/waf1 promoter, and induced p21/WAF1 expression [66]. Relatively little information is available in the literature for ING5. Doyon et al. recently identified MOZ (monocytic leukemia zinc finger protein)/MORF (MOZ related factor) and HBO1 to be catalytic native subunits of ING5 complexes, which are necessary for their activity [63]. The MOZ, and the related factor MORF also form tetrameric complexes with Esa1-associated factor 6 ortholog (EAF6), and the bromodomain- and PHD finger protein (BRPF)-1, -2, or -3. BRPF proteins are rich in domains found in chromatin-associated factors, like PHD fingers and bromodomain. Ullah and his group found that BRPF proteins bridge the association of MOZ and MORF with ING5 and a homolog of yeast Esa-1 associated factor 6 (EAF6) $[9,10,79]$. ING5 as an adapter molecule links the MOZ/MORF and HBO1/HAT complexes. PHD fingers of ING proteins recognize histone $\mathrm{H} 3$ methylated at lysine 4 at the chromatin, suggesting the functional role of ING5 in the chromatin remodeling process [79, 80].

\section{Disorders of ING family genes in human tumors}

Rearrangement of ING1 gene locus was demonstrated in one neuroblastoma cell line and reduced expression in primary cancers and cell lines in early clinical studies at the time of ING1 cloning [8-11]. Following ING1 cDNA cloning, we identified the genomic structure of the human ING1 gene and showed its tumor suppressor character for the first time by finding its chromosomal deletion at the $13 \mathrm{q} 34$ locus and tumor-specific mutations in a number of head and neck squamous cell carcinoma (HNSCC) samples [8].

Few studies have analyzed the mRNA expression status of ING family genes in various human cancers. Toyama et al. found decrease of ING1 mRNA expression in about half of breast cancer samples and all of the breast cancer cell lines they examined [47]. Another study also revealed reduced expression of breast cancer samples [81]. Down-regulation of ING1 mRNA has also been demonstrated in various other cancer types, including lymphoid malignancies, gastric tumors, brain tumors, lung cancer, ovarian cancer and esophagogastric carcinomas, though no comprehensive clinical correlation was performed $[9,10,15,16,82-90]$. Uncommon missense mutations and reduced protein expression of ING1 have also been 
detected in esophageal carcinomas [91], and colon cancer cell lines [83] while no mutation was detected in leukemia [84,92], oral cancers [93] and lymphoid malignancies [82].

For loss of ING gene and their protein functions, loss of heterozygosity (LOH), promoter CpG hypermetylation and nucleo-cytoplasmic protein mislocalization have been proposed $[9,10,15,16]$. Using methylation-specific PCR, the p33ING1b promoter was methylated and silenced in almost a quarter of all cases in primary ovarian tumors [89]. No differences or increased expression of ING1 were observed in recent studies of myeloid leukemia or melanoma [92,94].

Recently reduced expression of ING2 mRNA as well as protein was observed in hepatocellular carcinoma (HCC) [95]. Decreased ING2 expression (but not ING2 mutation) has been observed in lung cancer [96]. Decrease of nuclear ING2 protein was observed in melanoma [57]. On the other hand increased expression of ING2 mRNA was shown in colon cancer [97]. We recently demonstrated that frequent deletion of ING2 locus at 4q35.1 associated with advanced tumor stage in HNSCC [98]. Moreover, ING2 may play a role in melanoma initiation, since reduction of nuclear ING2 has been reported in radial as well as vertical growth phases, and metastatic melanoma as compared to dysplastic nevi [57]. On the other hand, reduced ING2 expression was associated with tumor progression and shortened survival time in HCC [95]. These epidemiological studies suggest that ING2 loss or reduction may be important for tumor initiation and/or progression $[9,10,15,16]$.

We showed frequent allelic loss of ING3 in HNSCC [42]. But ING3 mutation was very rare in our study (a sole missense mutation of ING3 at codon 20). In another recent study using a large study population, we revealed that down-regulation of ING3 was more evident in latestage tumors as compared with early stage patients, and patients with low ING3 mRNA expression demonstrated worse survival rates as compared to the patients with normal-high ING3 expression [99]. As shown for ING2, decreased nuclear ING3 protein expression was associated with a poor survival rate. The survival rate was $93 \%$ for the patients with strong nuclear ING3 staining, whereas it declined to $44 \%$ for the patients with negative-to-moderate nuclear staining [100]. In a recent study, we also demonstrated frequent deletion of chromosomal locus of each of ING family member including ING3 in ameloblastomas [101].

ING4 mRNA was decreased in glioblastoma and associated with tumor progression [70]. Decreased ING4 has been associated with increased expression of IL-8 and osteopontin (OPN) in myeloma $[9,102]$. In both reports, decreased ING4 expression was associated with higher tumor grade and increased tumor angiogenesis. In myeloma, it was also associated with increased expression of interleukin-8 and osteopontin [9,102]. Expression of ING4 was decreased in malignant melanoma as compared to dysplastic nevi, and was found to be an independent poor prognostic factor for the patients [73]. ING4 was found to suppress the loss of contact inhibition and growth. Moreover some mutation and deletion were detected in cell lines derived from human cancers such as breast and lung [103].

We reported reduced expression level of ING4 and frequent LOH of the ING4 locus in HNSCC [43]. No mutation of the ING4 gene was found in head and neck cancers. Significant reduced expression of ING4 was detected in gliomas as compared with normal human brain tissue, and the extent of reduction correlated with the progression from lower to higher grades of tumours [70]. Klironomos et al. investigated immunohistochemically the expression pattern of ING-4, NF-kappaB and the NF-kappaB downstream targets MMP-2, MMP-9 and u-PA in human astrocytomas from 101 patients. They found that ING-4 expression was significantly reduced in astrocytomas, and it was associated with tumor grade progression. Expression of a NF-kappaB subunit p65 was significantly higher in grade 
IV than in grade III and grade I/II tumors, and a statistical significant negative correlation between expression of ING-4 and expression of nuclear p65 was noticed [104].

Recently Nagahama et al. reported up-regulation of ING4 in a human gastric carcinoma cell line (MKN-1) by promoting mitochondria-mediated apoptosis via the activation of p53 [105]. Both mRNA and protein of ING4 expression were down regulated in hepatocellular carcinoma tissues. ING4 expression level correlated with prognosis and metastatic potential of hepatocellular carcinoma [106]. In another recent study, ING4 mRNA and protein expression were examined in gastric adenocarcinoma tissues and human gastric adenocarcinoma cell lines by RT-PCR, real-time RT-PCR, tissue microarray immunohistochemistry, and western blot analysis [107]. Their data showed that ING4 mRNA and protein were dramatically reduced in stomach adenocarcinoma cell lines and tissues, and significantly less in female than in male patients. Decrease of ING4 mRNA expression was found to correlate with the stage of the tumour [107]. Wang et al. examined ING4 protein expression in 246 lung cancer samples and overall reduced ING4 expression and higher ING4 expression in cytoplasm than in nucleus of tumour cells were detected, suggesting its involvement in the initiation and progression of lung cancers [108].

In a recent study, nuclear expression of ING4 was found to gradually decrease from noncancerous epithelium and dysplasia to HNSCC and was negatively correlated with a poorly-differentiated status, T staging, and TNM staging in HNSCC. On the other hand, cytoplasmic expression of ING4 was significantly enhanced in HNSCC and was significantly associated with lymph node metastasis and 14-3-3n expression. Moreover, nuclear expression of ING4 was positively correlated with p21 and p300 expression and with the apoptotic index. Their results suggested that the decreases in nuclear ING4 and cytoplasmic translocation of ING4 protein play important roles in tumorigenesis, progression and tumor differentiation in HNSCC [109].

Examination of ING4 protein expression levels in colorectal cancer samples from 97 patients showed that ING4 protein was down regulated in adenoma relative to normal mucosa and further reduced in colorectal cancer tissues. Decrease of ING4 protein expression was also related to the more advanced Dukes' stages and ING4 expression levels in patients with lymphatic metastasis were lower than those without metastasis, suggesting that ING4 play a role in colorectal carcinoma progression [110].

Our group reported the first study linking ING5 chromosome locus to a human cancer. We demonstrated a high ratio of $\mathrm{LOH}$ in oral cancer using 16 microsatellite markers on the long arm of chromosome 2q21-37.3 [111]. ING5 appeared to be a strong candidate tumor suppressor in this study though several other candidate TSGs including ILKAP, HDAC4, PPP1R7, DTYMK, STK25, BOK are also localized at the area, where frequent deletion has been detected $[9,10,111]$. Moreover, our recent study revealed decreased expression of ING5 mRNA and mutations in oral cancer samples as compared to their corresponding normal controls, suggesting its tumor suppressive role in cancer [45]. Examination of 172 cases of HNSCC for ING5 protein by immunohistochemistry using tissue microarray, and in 3 oral SCC cell lines by immunohistochemistry and Western blot showed that a decrease in nuclear ING5 localization and cytoplasmic translocation were detected, supporting the previous studies and strong involvement of ING5 in tumorigenesis and tumor differentiation in HNSCC [112].

Xing et al. analyzed ING5 expression in gastric carcinoma tissues and cell lines (MKN28, MKN45, AGS, GT-3 TKB, and KATO-III) by Western blot and reverse transcriptasepolymerase chain reaction. An increased expression of ING5 messenger RNA was found in 
gastric carcinoma in comparison with paired mucosa and lower expression of nuclear ING5 protein and cytoplasmic translocation was detected in gastric dysplasia and carcinoma than that in nonneoplastic mucosa [113]. Nuclear ING5 expression was negatively correlated with tumor size, depth of invasion, lymph node metastasis, and clinicopathologic staging, whereas cytoplasmic ING5 was positively associated with depth of invasion, venous invasion, lymph node metastasis, and clinicopathologic staging [113].

\section{Abnormalities of ING family genes in breast cancer}

Abnormalities of ING family members are linked to etiopathogenesis of various cancers including breast cancer. In fact, ING1, the founding member, was first isolated using a method that combined PCR-mediated subtractive hybridization of cDNAs from normal and breast cancerous cells [11]. Later same group examined ING1 mutation and mRNA expression in breast cancer cell lines and in a large number of primary breast cancers [47]. Within 377 breast cancer patients analyzed for mutation of ING1, one germ-line missense and three germ-line silent alterations were detected. Then mRNA analysis was randomly examined in 48 breast cancer samples. Their results showed that ING1 mRNA expression was decreased (2-10-fold) in $44 \%$ ( 21 out of 48 cases) of breast cancer tissues compared to adjacent normal tissues, while 33\% (16/48) of the tumors demonstrated levels similar to control sample and 23\% (11/48) showed increases in ING1 mRNA. All of the 10 breast cancer lines displayed decreased ING1 mRNA expression. Using in situ hybridization, decrease of mRNA in breast cancer cells was also confirmed as compared to adjacent normal cells. Using a monoclonal antibody against ING1, similar levels of the protein was also demonstrated in randomly selected 10 breast cancer samples [47]. When the relationship between ING1 mRNA expression levels and clinicopathological factors of breast cancer samples was examined, probability of metastasis to regional lymph nodes was significantly increased in ING1-decreased samples. Only one of 11 tumors (\%9) with increased ING1 mRNA expression metastasized to lymph nodes, whereas 11 of 19 cases (58\%) with decreased expression of ING1 showed metastasis to lymph nodes [47].

Tokunaga et al. examined the expression of ING1 mRNA in breast cancer cell lines and clinical breast cancer tissues, using quantitative RT-PCR and real-time TaqMan ${ }^{\mathrm{TM}}$ technology [81]. Decreased expression of ING1 mRNA was found in $71 \%$ of the breast cancer samples as compared to adjacent normal tissues. The authors has also examined p53 mutation status by immunohistochemistry and decreased ING1 expression was detected in 9 of 15 tumors that were negative for p53 immunostaining (i.e, wild type). Decrease of ING1 mRNA was speculated to be responsible for malfunction of p53 in these cases $[9,10,81]$. In an immunohistochemical study performed by Nouman et al, 69 (80\%) out of 86 breast cancer cases showed reduced expression of p33ING1b protein. On the other hand, strong nuclear expression of ING1 protein was detected in normal breast lobules and adjacent stroma. Correlation of each of estrogen and progesterone receptor status demonstrated a positive response with nuclear expression of p33ING1b protein. Nuclear loss of ING1 protein was associated with a concomitant enhancement of cytoplasmic p33ING1b expression in a proportion of the cases, suggesting as a cause for loss of normal function of the ING1 protein [114]. Similar reduced nuclear expression of p33ING1b protein was also shown in acute lymphoblastic leukemia [115], melanoma [116].

Toyama et al. reported that p33ING1b increased ER $\alpha$ transcriptional activity stimulated by estrogen through AF2 domain [10, 117]. In another research, p40, a protein highly 
homologous to breast carcinoma metastasis suppressor 1 (BRMS1), was found to be unit of the mammalian Sin3A co-repressor complex including RBP1 and p33ING1b and overexpression of $\mathrm{p} 40$ in human cells inhibited cell growth by recruiting the HDAC1 deacetylase complex. When tethered to the promoter by Gal-DNA binding domain, p40 can repress transcription of the luciferase reporter gene [118].

Kim et al. tried to identify genes that can suppress oncogenic properties such as loss of contact inhibition elicited by overexpression of MYCN. Their screen data revealed ING4 as a suppressor of loss of contact inhibition. Then they hypothesized that a deficiency of ING4 may play a role in tumorigenesis. For this aim, they examined ING4 transcripts in human cancer cell lines. They found a common deletion in various cancer cell lines including a breast cancer cell, T47D. Deletion of the four highly charged amino acid residues (KGKK) would result in mislocalization of the ING4 protein, thereby impairing its function [103]. Later this deletion was reported to be a source of alternative splicing variants of ING4 and was linked to abnormalities of subcellular localization of ING4 [71]. Besides Kim et al. also performed southern blot analysis for ING4 locus deletion in 55 breast cancer cell lines using 2 BAC probe within ING4 locus at 12p13.31. These probes, BAC RP11-272L6 and BAC RP11$59 \mathrm{H} 1$, were shown to be deleted in $24 \%$ and $11 \%$ of the cells including T47D breast cancer cell line, respectively [103].

In a recent study, ING4 was found to suppress an initial hyperplastic response to the oncogene MYC in a mouse model of breast cancer. In addition, they showed that a Cterminal truncation mutant of ING4 found in a human neuroblastoma cell line induced mammary hyperplasia and exacerbated MYC-initiated mammary tumorigenesis, suggesting that ING4 can function as a tumor suppressor gene in breast tissue [119].

In another recent report, therapeutic effect of adenovirus-mediated ING4 (Ad-ING4) gene therapy was investigated in human breast cancers in vitro and in vivo in an athymic nude mouse model, using two human breast carcinoma cell lines MDA-MB-231 (mutant p53) and MCF-7 (wild-type p53). The results displayed that Ad-ING4 treatment could induce in vitro significant growth suppression in both mutant p53 MDA-MB-231 and wild-type p53 MCF-7 breast carcinoma cells despite p53 status. Moreover the study further revealed that Ad-ING4 gene transfer resulted in G2/M phase arrest and apoptosis, upregulation of p21, p27, and Bax, downregulation of Bcl-2, IL-8, and Ang-1, promoted cytochrome c release from mitochondria into cytosol, and activated caspase-9, caspase-3, and PARP in mutant p53 MDA-MB-231 breast carcinoma cells. Furthermore, intratumoral injections of Ad-ING4 in nude mice bearing mutant p53 MDA-MB-231 breast tumors clearly inhibited the human breast xenografted tumor growth and decreased CD34 expression of tumor vessels and microvessel density. All these results suggest that Ad-ING4 is a potential candidate for breast cancer gene therapy [120].

ING4 was detected to be deleted in $170(16.5 \%)$ of 1033 breast cancer samples using two color FISH with a probe of BAC RP11-433J6 including ING4 locus. Comparison of clinicopathological variables with ING4 deletion status in these breast cancer samples showed significant difference for Her2 expression status. Thirty- nine $(23.8 \%)$ of 164 of tumors with ING4 deletion were HER2 positive, as compared with 115 (14.1\%) of 814 of tumors without deletion. In another way, 25.3\% (39/ 154) of HER2-positive tumors harbored ING4 deletion as compared to $15.1 \%$ (125/824) of HER2-negative tumors, indicating that ING4 deletion is more common in HER2- positive tumors [121]. In breast cancer, there is no report yet regarding with other members of ING family, ING2, 3 and 5. A summary of alterations of ING family genes in breast cancer is shown in table 1. 


\begin{tabular}{lcc}
\hline ING Gene & Alteration & Reference \\
\hline ING1 & Mutation, $\downarrow$ mRNA expression, $\downarrow$ protein expression & 47 \\
ING1 & $\downarrow$ mRNA expression & 81 \\
ING1 & Induction of ER $\alpha$ activity & 114 \\
ING1 & Deletion at chromosomal locus & 117 \\
ING4 & Suppression of MYC-induced carcinogenesis & 103 \\
ING4 & Ad-ING4-treated suppression of cancer cells and tumor & 119 \\
ING4 & growth & 120 \\
ING4 & Deletion at chromosomal locus & 121 \\
\hline
\end{tabular}

Table 1. Alterations of ING Family Genes in Breast Cancer.

\section{Future prospects}

Nearly 15 years of research after discovery of the first member of ING family gene, ING1, there are more accumulating data which show importance of these gene family in multiple cellular functions such as transcription, chromatin regulation, cell cycling, angiogenesis, cell transformation, apoptosis, growth regulation, senescence, DNA repair and tumorigenesis etc. Recent knowledge on this family displays that the family members have common and separate functions in human cancer. Though at the beginning, all members were considered to be tumor suppressor, recent evidences show a complex situation with oncogenic functions for at least some of the members and in some specific conditions. Thus both diagnostic and therapeutic approach should be revisited according to their functional roles in various conditions and tumor types. Though much work is necessary for clarifying the exact functions of these genes to provide therapy for various human cancers, promising results are noticed at the moment for usability of these genes as a therapeutic and diagnostic target. Thus progress on the knowledge of functions of ING family genes as well as the relationship with p53 and other unknown molecules will clarify their roles in cancer, which will result in their uses in cancer diagnostics as well as therapy soon.

\section{References}

[1] Hinds PW and Weinberg RA. Tumor suppressor genes. Curr Opin Genet Dev 4: 135-141, 1994

[2] Knudson AG Jr. Mutation and cancer: statistical study of retinoblastoma. Proc Natl Acad Sci USA 68: 820-823, 1971

[3] Tang B, Bottinger EP, Jakowlew SB, Bagnall KM, Mariano J, Anver MR, Letterio JJ and Wakefield LM. Transforming growth factor-b1 is a new form of tumor suppressor with true haploid insufficiency. Nat Med 4: 802-807, 1998 
[4] Bai F, Pei XH, Godfrey VL and Xiong Y. Haploinsufficiency of p18 (INK4c) sensitizes mice to carcinogen-induced tumorigenesis. Mol Cell Biol 23: 1269-1277, 2003

[5] Mduff FK, Hook CE, Tooze RM, Huntly BJ, Pandolfi PP, Turner SD. Determining the contribution of NPM1 heterozygosity to NPM-ALK-induced lymphomagenesis. Lab Invest. 2011 Jun 27. doi: 10.1038/labinvest.2011.96. [Epub ahead of print]

[6] Huang H, Wei X, Su X, Qiao F, Xu Z, Gu D, Fan H, Chen J. Clinical significance of expression of Hint1 and potential epigenetic mechanism in gastric cancer. Int $\mathrm{J}$ Oncol 38:1557-64, 2011

[7] Zhou XZ, Huang P, Shi R, Lee TH, Lu G, Zhang Z, Bronson R, Lu KP. The telomerase inhibitor PinX1 is a major haploinsufficient tumor suppressor essential for chromosome stability in mice. J Clin Invest 121(4):1266-82, 2011

[8] Gunduz M, Ouchida M, Fukushima K, Hanafusa H, Etani T, Nishioka S, Nishizaki K and Shimizu K. Genomic structure of the human ING1 gene and tumor-specific mutations detected in head and neck squamous cell carcinomas. Cancer Res 60: 3143-3146, 2000

[9] Gunduz M, Gunduz E, Rivera RS, Nagatsuka H. The inhibitor of growth (ING) gene family: potential role in cancer therapy. Curr Cancer Drug Targets 8:275-84, 2008

[10] Gunduz M, Demircan K, Gunduz E, Katase N, Tamamura R, Nagatsuka H. Potential usage of ING family members in cancer diagnostics and molecular therapy. Curr Drug Targets. 10(5):465-76, 2009

[11] Garkavtsev I, Kazarov A, Gudkov A and Riabowol K. Suppression of the novel growth inhibitor p33ING1 promotes neoplastic transformation. Nat Genet 14: 415-420, 1996

[12] Helbing CC, Veilette C, Riabowol K, Johnston RN and Garkavtsev I. A novel candidate tumor suppressor gene, ING1, is involved in the regulation of apoptosis. Cancer Res 57: 1255-1258, 1997

[13] Zeremski M, Horrigan SK, Grigorian IA, Westbrook CA and Gudkov AV. Localization of the candidate tumor suppressor gene ING1 to human chromosome 13q34. Somatic Cell Mol Genet 23: 233-236, 1997

[14] Feng X, Hara Y and Riabowol K. Different HATS of the ING1 gene family. Trends Cell Biol 12: 532-538, 2002

[15] Aguissa-Touré AH, Wong RP, Li G. Cell Mol Life Sci. The ING family tumor suppressors: from structure to function. 68:45-54, 2011

[16] Coles AH, Jones SN. The ING gene family in the regulation of cell growth and tumorigenesis. J Cell Physiol 218:45-57, 2009

[17] Unoki M, Kumamoto K, Harris CC. ING proteins as potential anticancer drug targets. Curr Drug Targets 10:442-54, 2009

[18] Aasland R, Gibson TJ, Stewart AF. The PHD finger: implications for chromatinmediated transcriptional regulation. Trends Biochem Sci 20:56-59, 1995

[19] Shimada Y, Saito A, Suzuki M, Takahashi E, Horie M. Cloning of a novel gene (ING1L) homologous to ING1, a candidate tumor suppressor. Cytogenet Cell Genet 83:232235, 1998

[20] Ha S, Park S, Yun CH, Choi Y. Characterization of nuclear localization signal in mouse ING1 homolog protein. Biochem Biophys Res Commun 293:163-166, 2002

[21] Scott M, Boisvert FM, Vieyra D, Johnston RN, Bazett-Jones DP, Riabowol K. UV induces nucleolar translocation of ING1 through two distinct nucleolar targeting sequences. Nucleic Acids Re 29:2052-2058, 2001 
[22] Zeremski M, Hill JE, Kwek SS, Grigorian IA, Gurova KV, Garkavtsev IV, Diatchenko L, Koonin EV, Gudkov AV. Structure and regulation of the mouse ing1 gene. Three alternative transcripts encode two phd finger proteins that have opposite effects on p53 function. J Biol Chem 274:32172-32181, 1999

[23] Pascual J, Martinez-Yamout M, Dyson HJ, Wright PE. Structure of the PHD zinc finger from human Williams-Beuren syndrome transcription factor. J Mol Biol 304:723-9, 2000

[24] Gibbons RJ, Bachoo S, Picketts DJ, Aftimos S, Asenbauer B, Bergoffen J, Berry SA, Dahl N, Fryer A, Keppler K, Kurosawa K, Levin ML, Masuno M, Neri G, Pierpont ME, Slaney SF, Higgs DR. Mutations in transcriptional regulator ATRX establish the functional significance of a PHD-like domain. Nat Genet 17:146-8, 1997

[25] Saugier-Veber P, Drouot N, Wolf LM, Kuhn JM, Frébourg T, Lefebvre H. Identification of a novel mutation in the autoimmune regulator (AIRE-1) gene in a French family with autoimmune polyendocrinopathy-candidiasis-ectodermal dystrophy. Eur J Endocrinol 144:347-51, 2001

[26] Elkin SK, Ivanov D, Ewalt M, Ferguson CG, Hyberts SG, Sun ZY, Prestwich GD, Yuan J, Wagner G, Oettinger MA, Gozani OP. A PHD finger motif in the C terminus of RAG2 modulates recombination activity. J Biol Chem 280:28701-10, 2005

[27] Han X, Feng X, Rattner JB, Smith H, Bose P, Suzuki K, Soliman MA, Scott MS, Burke BE, Riabowol K. Tethering by lamin A stabilizes and targets the ING1 tumour suppressor. Nat Cell Biol 10:1333-1340, 2008

[28] Scott M, Boisvert FM, Vieyra D, Johnston RN, Bazett-Jones DP, Riabowol K. UV induces nucleolar translocation of ING1 through two distinct nucleolar targeting sequences. Nucleic Acids Res 29:2052-2058, 2001

[29] Ha S, Park S, Yun CH, Choi Y. Characterization of nuclear localization signal in mouse ING1 homolog protein. Biochem Biophys Res Commun 293:163-166, 2002

[30] Gong W, Suzuki K, Russell M, Riabowol K. Function of the ING family of PHD proteins in cancer. Int J Biochem Cell Biol 37:1054-1065, 2005

[31] Zhang X, Wang KS, Wang ZQ, Xu LS, Wang QW, Chen F, Wei DZ, Han ZG. Nuclear localization signal of ING4 plays a key role in its binding to p53. Biochem Biophys Res Commun 331:1032-1038, 2005

[32] Soliman MA, Riabowol K. After a decade of study-ING, a PHD for a versatile family of proteins. Trends Biochem Sci 32:509-519, 2007

[33] He GH, Helbing CC, Wagner MJ, Sensen CW, Riabowol K. Phylogenetic analysis of the ING family of PHD finger proteins. Mol Biol Evol 22:104-116, 2005

[34] Wang Y, Wang J, Li G. Leucine zipper-like domain is required for tumor suppressor ING2-mediated nucleotide excision repair and apoptosis. FEBS Lett 580:3787-3793, 2006

[35] Wang J, Chin MY, Li G. The novel tumor suppressor p33ING2 enhances nucleotide excision repair via inducement of histone $\mathrm{H} 4$ acetylation and chromatin relaxation. Cancer Res 66:1906-1911, 2006

[36] Scott M, Bonnefin P, Vieyra D, Boisvert FM, Young D, Bazett- Jones DP, Riabowol K. UV-induced binding of ING1 to PCNA regulates the induction of apoptosis. J Cell Sci 114:3455-3462, 2001 
[37] Kuzmichev A, Zhang Y, Erdjument-Bromage H, Tempst P, Reinberg D. Role of the Sin3histone deacetylase com- plex in growth regulation by the candidate tumor suppressor p33(ING1). Mol Cell Biol 22:835-848, 2002

[38] Kaadige MR, Ayer DE. The polybasic region that follows the plant homeodomain zinc finger 1 of Pf1 is necessary and sufficient for specific phosphoinositide binding. J Biol Chem 281:28831-28836, 2006

[39] Huang W, Zhang H, Davrazou F, Kutateladze TG, Shi X, Gozani O, Prestwich GD. Stabilized phosphatidylinositol- 5-phosphate analogues as ligands for the nuclear protein ING2: chemistry, biology, and molecular modeling. J Am Chem Soc 129:6498-6506, 2007

[40] Unoki M, Kumamoto K, Robles AI, Shen JC, Zheng ZM, Harris CC. A novel ING2 isoform, ING2b, synergizes with ING2a to prevent cell cycle arrest and apoptosis. FEBS Lett 582:3868-74, 2008

[41] Unoki M, Kumamoto K, Takenoshita S, Harris CC. Reviewing the current classification of inhibitor of growth family proteins. Cancer Sci 100:1173-9, 2009

[42] Gunduz M, Ouchida M, Fukushima K, Ito S, Jitsumori Y, Nakashima T, Nagai N, Nishizaki K, Shimizu K. Allelic loss and reduced expression of the ING3, a candidate tumor suppressor gene at 7q31, in human head and neck cancers. Oncogene 21:4462-70, 2002

[43] Gunduz M, Nagatsuka H, Demircan K, Gunduz E, Cengiz B, Ouchida M, Tsujigiwa H, Yamachika E, Fukushima K, Beder L, Hirohata S, Ninomiya Y, Nishizaki K, Shimizu K, Nagai N. Frequent deletion and down-regulation of ING4, a candidate tumor suppressor gene at $12 \mathrm{p} 13$, in head and neck squamous cell carcinomas. Gene 15;356:109-117, 2005

[44] Ythier D, Larrieu D, Brambilla C, Brambilla E, Pedeux R. The new tumor suppressor genes ING: genomic structure and status in cancer. Int J Cancer 123:1483-90, 2008

[45] Cengiz B, Gunduz E, Gunduz M, Beder LB, Tamamura R, Bagci C, Yamanaka N, Shimizu K, Nagatsuka H. Tumor-specific mutation and downregulation of ING5 detected in oral squamous cell carcinoma. Int J Cancer 127:2088-94, 2010

[46] Campos EI, Chin MY, Kuo WH, Li G. Biological functions of the ING family tumor suppressors. Cell Mol Life Sci 61(19-20):2597-613, 2004

[47] Toyama T, Iwase H, Watson P, Muzik H, Saettler E, Magliocco A, DiFrancesco L, Forsyth P, Garkavtsev I, Kobayashi S, Riabowol K. Suppression of ING1 expression in sporadic breast cancer. Oncogene 18:5187-93, 1999

[48] Coles AH, Liang H, Zhu Z, Marfella CG, Kang J, Imbalzano AN, Jones SN. Deletion of p37Ing1 in mice reveals a p53-independent role for Ing1 in the suppression of cell proliferation, apoptosis, and tumorigenesis. Cancer Res 67:2054-61, 2007

[49] Ozer A, Bruick RK. Regulation of HIF by prolyl hydroxylases: recruitment of the candidate tumor suppressor protein ING4. Cell Cycle 4:1153-6, 2005

[50] Ozer A, Wu LC, Bruick RK. The candidate tumor suppressor ING4 represses activation of the hypoxia inducible factor (HIF). Proc Natl Acad Sci U S A 102:7481-6, 2005

[51] Coles AH, Gannon H, Cerny A, Kurt-Jones E, Jones SN. Inhibitor of growth-4 promotes IkappaB promoter activation to suppress NF-kappaB signaling and innate immunity. Proc Natl Acad Sci U S A 107:11423-8, 2010 
[52] Nozell S, Laver T, Moseley D, Nowoslawski L, De Vos M, Atkinson GP, Harrison K, Nabors LB, Benveniste EN. The ING4 tumor suppressor attenuates NF-kappaB activity at the promoters of target genes. Mol Cell Biol 28:6632-45, 2008

[53] Nagashima M, Shiseki M, Miura K, Hagiwara K, Linke SP, Pedeux R, Wang XW, Yokota J, Riabowol K, Harris CC. DNA damage-inducible gene p33ING2 negatively regulates cell proliferation through acetylation of p53. Proc Natl Acad Sci U S A 98:9671-6, 2001

[54] Pedeux R, Sengupta S, Shen JC, Demidov ON, Saito S, Onogi H, Kumamoto K, Wincovitch S, Garfield SH, McMenamin M, Nagashima M, Grossman SR, Appella $\mathrm{E}$, Harris CC. ING2 regulates the onset of replicative senescence by induction of p300-dependent p53 acetylation. Mol Cell Biol 25:6639-48, 2005

[55] Sarker KP, Kataoka H, Chan A, Netherton SJ, Pot I, Huynh MA, Feng X, Bonni A, Riabowol K, Bonni S. ING2 as a novel mediator of transforming growth factor-betadependent responses in epithelial cells. J Biol Chem 283:13269-79, 2008

[56] Borkosky SS, Gunduz M, Nagatsuka H, Beder LB, Gunduz E, Ali MA, Rodriguez AP, Cilek MZ, Tominaga S, Yamanaka N, Shimizu K, Nagai N. Frequent deletion of ING2 locus at 4q35.1 associates with advanced tumor stage in head and neck squamous cell carcinoma. J Cancer Res Clin Oncol 135:703-13, 2009

[57] Lu F, Dai DL, Martinka M, Ho V, Li G. Nuclear ING2 expression is reduced in human cutaneous melanomas. Br J Cancer 95:80-6, 2006

[58] Larrieu D, Ythier D, Binet R, Brambilla C, Brambilla E, Sengupta S, Pedeux R. ING2 controls the progression of DNA replication forks to maintain genome stability. EMBO Rep 10:1168-74, 2009

[59] Nagashima M, Shiseki M, Pedeux RM, Okamura S, Kitahama-Shiseki M, Miura K, Yokota J, Harris CC. A novel PHD-finger motif protein, p47ING3, modulates p53mediated transcription, cell cycle control, and apoptosis. Oncogene 22:343-50, 2003

[60] Doyon Y, Côté J.The highly conserved and multifunctional NuA4 HAT complex. Curr Opin Genet Dev 14:147-5, 2004

[61] Kataoka H, Bonnefin P, Vieyra D, Feng X, Hara Y, Miura Y, Joh T, Nakabayashi H, Vaziri H, Harris CC, Riabowol K. ING1 represses transcription by direct DNA binding and through effects on p53. Cancer Res 63:5785-92, 2003

[62] Doyon Y, Selleck W, Lane WS, Tan S, Côté J. Structural and functional conservation of the NuA4 histone acetyltransferase complex from yeast to humans. Mol Cell Biol 24:1884-9, 2004

[63] Doyon Y, Cayrou C, Ullah M, Landry AJ, Côté V, Selleck W, Lane WS, Tan S, Yang XJ, Côté J. ING tumor suppressor proteins are critical regulators of chromatin acetylation required for genome expression and perpetuation. Mol Cell 21:51-64, 2006

[64] Wang Y, Li G. J. ING3 promotes UV-induced apoptosis via Fas/caspase-8 pathway in melanoma cells. Biol Chem 281:11887-93, 2006

[65] Chen G, Wang Y, Garate M, Zhou J, Li G. The tumor suppressor ING3 is degraded by SCF (Skp2)-mediated ubiquitin-proteasome system. Oncogene 29:1498-508, 2010

[66] Shiseki M, Nagashima M, Pedeux RM, Kitahama-Shiseki M, Miura K, Okamura S, Onogi H, Higashimoto Y, Appella E, Yokota J, Harris CC. p29ING4 and p28ING5 bind to p53 and p300, and enhance p53 activity. Cancer Res 63:2373-8, 2003

[67] Li J, Li G. Cell cycle regulator ING4 is a suppressor of melanoma angiogenesis that is regulated by the metastasis suppressor BRMS1. Cancer Res 70:10445-53, 2010 
[68] Xie YF, Sheng W, Xiang J, Zhang H, Ye Z, Yang J. Adenovirus-mediated ING4 expression suppresses pancreatic carcinoma cell growth via induction of cell-cycle alteration, apoptosis, and inhibition of tumor angiogenesis. Cancer Biother Radiopharm 24:261-9, 2009

[69] Zhu Y, Lv H, Xie Y, Sheng W, Xiang J, Yang J. Enhanced tumor suppression by an ING4/IL-24 bicistronic adenovirus-mediated gene cotransfer in human non-small cell lung cancer cells. Cancer Gene Ther. 2011 Jun 10. doi: 10.1038/cgt.2011.31. [Epub ahead of print]

[70] Garkavtsev I, Kozin SV, Chernova O, Xu L, Winkler F, Brown E, Barnett GH, Jain RK. The candidate tumour suppressor protein ING4 regulates brain tumour growth and angiogenesis. Nature 428:328-32, 2004

[71] Unoki M, Shen JC, Zheng ZM, Harris CC. Novel splice variants of ING4 and their possible roles in the regulation of cell growth and motility. J Biol Chem 281:3467786, 2006

[72] Shen JC, Unoki M, Ythier D, Duperray A, Varticovski L, Kumamoto K, Pedeux R, Harris CC. Inhibitor of growth 4 suppresses cell spreading and cell migration by interacting with a novel binding partner, liprin alpha1. Cancer Res 67:2552-8, 2007

[73] Li J, Martinka M, Li G. Role of ING4 in human melanoma cell migration, invasion and patient survival. Carcinogenesis 29:1373-9, 2008

[74] Cai L, Li X, Zheng S, Wang Y, Wang Y, Li H, Yang J, Sun J. Inhibitor of growth 4 is involved in melanomagenesis and induces growth suppression and apoptosis in melanoma cell line M14. Melanoma Res 19:1-7, 2009

[75] Li X, Cai L, Chen H, Zhang Q, Zhang S, Wang Y, Dong Y, Cheng H, Qi J. Inhibitor of growth 4 induces growth suppression and apoptosis in glioma U87MG. Pathobiology 76:181-92, 2009

[76] Saksouk N, Avvakumov N, Champagne KS, Hung T, Doyon Y, Cayrou C, Paquet E, Ullah M, Landry AJ, Côté V, Yang XJ, Gozani O, Kutateladze TG, Côté J. HBO1 HAT complexes target chromatin throughout gene coding regions via multiple PHD finger interactions with histone $\mathrm{H} 3$ tail. Mol Cell 33:257-65, 2009

[77] Hung T, Binda O, Champagne KS, Kuo AJ, Johnson K, Chang HY, Simon MD, Kutateladze TG, Gozani O. ING4 mediates crosstalk between histone H3 K4 trimethylation and $\mathrm{H} 3$ acetylation to attenuate cellular transformation. Mol Cell 33:248-56, 2009

[78] Zhang X, Xu LS, Wang ZQ, Wang KS, Li N, Cheng ZH, Huang SZ, Wei DZ, Han ZG. ING4 induces G2/M cell cycle arrest and enhances the chemosensitivity to DNAdamage agents in HepG2 cells. FEBS Lett 570:7-12, 2004

[79] Ullah M, Pelletier N, Xiao L, Zhao SP, Wang K, Degerny C, Tahmasebi S, Cayrou C, Doyon Y, Goh SL, Champagne N, Côté J, Yang XJ. Molecular architecture of quartet MOZ/MORF histone acetyltransferase complexes. Mol Cell Biol 28:6828-43, 2008 Erratum in: Mol Cell Biol. 2009 Feb;29:942

[80] Champagne KS, Saksouk N, Peña PV, Johnson K, Ullah M, Yang XJ, Côté J, Kutateladze TG. The crystal structure of the ING5 PHD finger in complex with an H3K4me3 histone peptide. Proteins 72:1371-6, 2008

[81] Tokunaga E, Maehara Y, Oki E, Kitamura K, Kakeji Y, Ohno S, Sugimachi K. Diminished expression of ING1 mRNA and the correlation with p53 expression in breast cancers. Cancer Lett 152:15-22, 2000 
[82] Ohmori M, Nagai M, Tasaka T, Koeffler HP, Toyama T, Riabowol K, Takahara J. Decreased expression of p33ING1 mRNA in lymphoid malignancies. Am J Hematol 62:118-9, 1999 Erratum in: Am J Hematol 2000 May;64(1):82.

[83] Oki E, Maehara Y, Tokunaga E, Kakeji Y, Sugimachi K. Reduced expression of p33 (ING1) and the relationship with p53 expression in human gastric cancer. Cancer Lett 147:157-62, 1999

[84] Ito K, Kinjo K, Nakazato T, Ikeda Y, Kizaki M. Expression and sequence analyses of p33(ING1) gene in myeloid leukemia. Am J Hematol 69:141-3, 2002

[85] Hara Y, Zheng Z, Evans SC, Malatjalian D, Riddell DC, Guernsey DL, Wang LD, Riabowol K, Casson AG. ING1 and p53 tumor suppressor gene alterations in adenocarcinomas of the esophagogastric junction. Cancer Lett 192:109-16, 2003

[86] Tallen G, Riabowol K, Wolff JE. Expression of p33ING1 mRNA and chemosensitivity in brain tumor cells. Anticancer Res 23(2B):1631-5, 2003

[87] Tallen G, Kaiser I, Krabbe S, Lass U, Hartmann C, Henze G, Riabowol K, von Deimling A. No ING1 mutations in human brain tumours but reduced expression in high malignancy grades of astrocytoma. Int J Cancer 109:476-9, 2004

[88] Takahashi M, Ozaki T, Todo S, Nakagawara A. Decreased expression of the candidate tumor suppressor gene ING1 is associated with poor prognosis in advanced neuroblastomas. Oncol Rep 12:811-6, 2004

[89] Shen DH, Chan KY, Khoo US, Ngan HY, Xue WC, Chiu PM, Ip P, Cheung AN. Epigenetic and genetic alterations of p33ING1b in ovarian cancer. Carcinogenesis 26:855-63, 2005

[90] Kameyama K, Huang CL, Liu D, Masuya D, Nakashima T, Sumitomo S, Takami Y, Kinoshita M, Yokomise H. Reduced ING1b gene expression plays an important role in carcinogenesis of non-small cell lung cancer patients. Clin Cancer Res 9:4926-34, 2003

[91] Chen L, Matsubara N, Yoshino T, Nagasaka T, Hoshizima N, Shirakawa Y, Naomoto Y, Isozaki H, Riabowol K, Tanaka N. Genetic alterations of candidate tumor suppressor ING1 in human esophageal squamous cell cancer. Cancer Res 61:4345-9, 2001

[92] Bromidge T, Lynas C. Relative levels of alternative transcripts of the ING1 gene and lack of mutations of p33/ING1 in haematological malignancies. Leuk Res 26:631-5, 2002

[93] Krishnamurthy J, Kannan K, Feng J, Mohanprasad BK, Tsuchida N, Shanmugam G. Mutational analysis of the candidate tumor suppressor gene ING1 in Indian oral squamous cell carcinoma. Oral Oncol 37:222-4, 2001

[94] Stark M, Puig-Butille JA, Walker G, Badenas C, Malvehy J, Hayward N, Puig S. Mutation of the tumour suppressor p33ING1b is rare in melanoma. Br J Dermatol 155:94-9, 2006

[95] Zhang HK, Pan K, Wang H, Weng DS, Song HF, Zhou J, Huang W, Li JJ, Chen MS, Xia JC. Decreased expression of ING2 gene and its clinicopathological significance in hepatocellular carcinoma. Cancer Lett 261:183-92, 2008

[96] Okano T, Gemma A, Hosoya Y, Hosomi Y, Nara M, Kokubo Y, Yoshimura A, Shibuya M, Nagashima M, Harris CC, Kudoh S. Alterations in novel candidate tumor suppressor genes, ING1 and ING2 in human lung cancer. Oncol Rep 15:545-9, 2006 
[97] Kumamoto K, Fujita K, Kurotani R, Saito M, Unoki M, Hagiwara N, Shiga H, Bowman ED, Yanaihara N, Okamura S, Nagashima M, Miyamoto K, Takenoshita S, Yokota J, Harris CC. ING2 is upregulated in colon cancer and increases invasion by enhanced MMP13 expression. Int J Cancer 125:1306-15, 2009

[98] Borkosky SS, Gunduz M, Nagatsuka H, Beder LB, Gunduz E, Ali MA, Rodriguez AP, Cilek MZ, Tominaga S, Yamanaka N, Shimizu K, Nagai N. Frequent deletion of ING2 locus at 4q35.1 associates with advanced tumor stage in head and neck squamous cell carcinoma. J Cancer Res Clin Oncol 135:703-13, 2009

[99] Gunduz M, Beder LB, Gunduz E, Nagatsuka H, Fukushima K, Pehlivan D, Cetin E, Yamanaka N, Nishizaki K, Shimizu K, Nagai N. Downregulation of ING3 mRNA expression predicts poor prognosis in head and neck cancer. Cancer Sci 99:531-8, 2008

[100] Wang Y, Dai DL, Martinka M, Li G. Prognostic significance of nuclear ING3 expression in human cutaneous melanoma. Clin Cancer Res 13:4111-6, 2007

[101] Borkosky SS, Gunduz M, Beder L, Tsujigiwa H, Tamamura R, Gunduz E, Katase N, Rodriguez AP, Sasaki A, Nagai N, Nagatsuka H. Allelic loss of the ING gene family loci is a frequent event in ameloblastoma. Oncol Res 18:509-18, 2010

[102] Colla S, Tagliaferri S, Morandi F, Lunghi P, Donofrio G, Martorana D, Mancini C, Lazzaretti M, Mazzera L, Ravanetti L, Bonomini S, Ferrari L, Miranda C, Ladetto M, Neri TM, Neri A, Greco A, Mangoni M, Bonati A, Rizzoli V, Giuliani N. The new tumor-suppressor gene inhibitor of growth family member 4 (ING4) regulates the production of proangiogenic molecules by myeloma cells and suppresses hypoxiainducible factor-1 alpha (HIF-1alpha) activity: involvement in myeloma-induced angiogenesis. Blood 110:4464-75, 2007. Epub 2007 Sep 11. Erratum in Blood. 2008 Sep 1;112:2170.

[103] Kim S, Chin K, Gray JW, Bishop JM. A screen for genes that suppress loss of contact inhibition: identification of ING4 as a candidate tumor suppressor gene in human cancer. Proc Natl Acad Sci U S A 101:16251-6, 2004

[104] Klironomos G, Bravou V, Papachristou DJ, Gatzounis G, Varakis J, Parassi E, Repanti M, Papadaki H. Loss of inhibitor of growth (ING-4) is implicated in the pathogenesis and progression of human astrocytomas. Brain Pathol 20:490-7, 2010

[105] Nagahama Y, Ishimaru M, Osaki M, Inoue T, Maeda A, Nakada C, Moriyama M, Sato $\mathrm{K}$, Oshimura M, Ito H. Apoptotic pathway induced by transduction of RUNX3 in the human gastric carcinoma cell line MKN-1. Cancer Sci 99:23-30, 2008

[106] Fang F, Luo LB, Tao YM, Wu F, Yang LY. Decreased expression of inhibitor of growth 4 correlated with poor prognosis of hepatocellular carcinoma. Cancer Epidemiol Biomarkers Prev 18:409-16, 2009

[107] Li M, Jin Y, Sun WJ, Yu Y, Bai J, Tong DD, Qi JP, Du JR, Geng JS, Huang Q, Huang XY, Huang Y, Han FF, Meng XN, Rosales JL, Lee KY, Fu SB. Reduced expression and novel splice variants of ING4 in human gastric adenocarcinoma. J Pathol 219:87-95, 2009

[108] Wang QS, Li M, Zhang LY, Jin Y, Tong DD, Yu Y, Bai J, Huang Q, Liu FL, Liu A, Lee $\mathrm{KY}, \mathrm{Fu} \mathrm{SB}$. Down-regulation of ING4 is associated with initiation and progression of lung cancer. Histopathology 57:271-81, 2010

[109] Li XH, Kikuchi K, Zheng Y, Noguchi A, Takahashi H, Nishida T, Masuda S, Yang XH, Takano Y. Downregulation and translocation of nuclear ING4 is correlated with 
tumorigenesis and progression of head and neck squamous cell carcinoma. Oral Oncol 47:217-23, 2011

[110] You Q, Wang XS, Fu SB, Jin XM. Downregulated Expression of Inhibitor of Growth 4 (ING4) in Advanced Colorectal Cancers: A Non-Randomized Experimental Study. Pathol Oncol Res. 2011 May 31. [Epub ahead of print]

[111] Cengiz B, Gunduz M, Nagatsuka H, Beder L, Gunduz E, Tamamura R, Mahmut N, Fukushima K, Ali MA, Naomoto Y, Shimizu K, Nagai N. Fine deletion mapping of chromosome 2q21-37 shows three preferentially deleted regions in oral cancer. Oral Oncol 43:241-7, 2007

[112] Li X, Nishida T, Noguchi A, Zheng Y, Takahashi H, Yang X, Masuda S, Takano Y. Decreased nuclear expression and increased cytoplasmic expression of ING5 may be linked to tumorigenesis and progression in human head and neck squamous cell carcinoma. J Cancer Res Clin Oncol 136:1573-83, 2010

[113] Xing YN, Yang X, Xu XY, Zheng Y, Xu HM, Takano Y, Zheng HC. The altered expression of ING5 protein is involved in gastric carcinogenesis and subsequent progression. Hum Pathol 42:25-35, 2011

[114] Zheng HC, Xia P, Xu XY, Takahashi H, Takano Y. The nuclear to cytoplasmic shift of ING5 protein during colorectal carcinogenesis with their distinct links to pathologic behaviors of carcinomas. Hum Pathol 42:424-33, 2011

[115] Nouman GS, Anderson JJ, Crosier S, Shrimankar J, Lunec J, Angus B. Downregulation of nuclear expression of the p33(ING1b) inhibitor of growth protein in invasive carcinoma of the breast. J Clin Pathol 56:507-11, 2003

[116] Nouman GS, Anderson JJ, Wood KM, Lunec J, Hall AG, Reid MM, Angus B. Loss of nuclear expression of the p33(ING1b) inhibitor of growth protein in childhood acute lymphoblastic leukaemia. J Clin Pathol 55:596-601, 2002

[117] Nouman GS, Anderson JJ, Mathers ME, Leonard N, Crosier S, Lunec J, Angus B. Nuclear to cytoplasmic compartment shift of the p33ING1b tumour suppressor protein is associated with malignancy in melanocytic lesions. Histopathology 40:360-6, 2002

[118] Toyama T, Iwase H, Yamashita H, Hara Y, Sugiura H, Zhang Z, Fukai I, Miura Y, Riabowol K, Fujii Y. p33(ING1b) stimulates the transcriptional activity of the estrogen receptor alpha via its activation function (AF) 2 domain. J Steroid Biochem Mol Biol 87:57-63, 2003

[119] Nikolaev AY, Papanikolaou NA, Li M, Qin J, Gu W. Identification of a novel BRMS1homologue protein $\mathrm{p} 40$ as a component of the mSin3A/p33(ING1b)/HDAC1 deacetylase complex. Biochem Biophys Res Commun 323:1216-22, 2004

[120] Kim S, Welm AL, Bishop JM. A dominant mutant allele of the ING4 tumor suppressor found in human cancer cells exacerbates MYC-initiated mouse mammary tumorigenesis. Cancer Res 70:5155-62, 2010

[121] Li Z, Xie Y, Sheng W, Miao J, Xiang J, Yang J. Tumor-suppressive effect of adenovirusmediated inhibitor of growth 4 gene transfer in breast carcinoma cells in vitro and in vivo. Cancer Biother Radiopharm 25:427-37, 2010

[122] Tapia C, Zlobec I, Schneider S, Kilic E, Güth U, Bubendorf L, Kim S. Deletion of the inhibitor of growth 4 (ING4) tumor suppressor gene is prevalent in human epidermal growth factor 2 (HER2)-positive breast cancer. Hum Pathol 42:983-90, 2011 


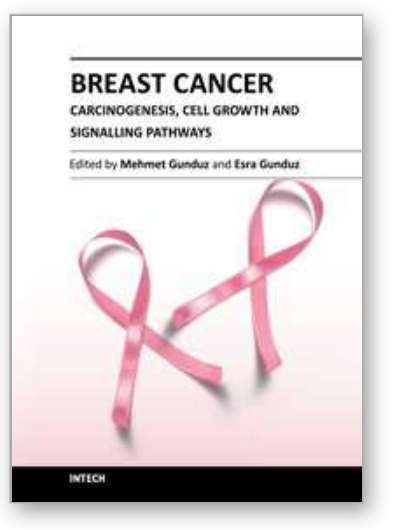

\author{
Breast Cancer - Carcinogenesis, Cell Growth and Signalling \\ Pathways \\ Edited by Prof. Mehmet Gunduz
}

ISBN 978-953-307-714-7

Hard cover, 732 pages

Publisher InTech

Published online 30, November, 2011

Published in print edition November, 2011

Cancer is the leading cause of death in most countries and its consequences result in huge economic, social and psychological burden. Breast cancer is the most frequently diagnosed cancer type and the leading cause of cancer death among females. In this book, we discussed various aspects of breast cancer carcinogenesis from clinics to its hormone-based as well as genetic-based etiologies for this deadly cancer. We hope that this book will contribute to the development of novel diagnostic as well as therapeutic approaches.

\title{
How to reference
}

In order to correctly reference this scholarly work, feel free to copy and paste the following:

Mehmet Gunduz, Esra Gunduz, Mikdat Bozer and Ramazan Yigitoglu (2011). Role of ING Family Tumor Suppressors in Breast Cancer, Breast Cancer - Carcinogenesis, Cell Growth and Signalling Pathways, Prof. Mehmet Gunduz (Ed.), ISBN: 978-953-307-714-7, InTech, Available from:

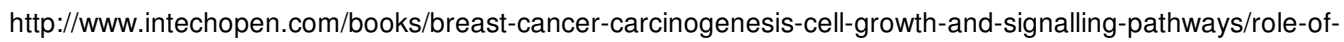
ing-family-tumor-suppressors-in-breast-cancer

\section{INTECH}

open science | open minds

\section{InTech Europe}

University Campus STeP Ri

Slavka Krautzeka 83/A

51000 Rijeka, Croatia

Phone: +385 (51) 770447

Fax: +385 (51) 686166

www.intechopen.com

\section{InTech China}

Unit 405, Office Block, Hotel Equatorial Shanghai

No.65, Yan An Road (West), Shanghai, 200040, China

中国上海市延安西路65号上海国际贵都大饭店办公楼 405 单元

Phone: +86-21-62489820

Fax: +86-21-62489821 
(C) 2011 The Author(s). Licensee IntechOpen. This is an open access article distributed under the terms of the Creative Commons Attribution 3.0 License, which permits unrestricted use, distribution, and reproduction in any medium, provided the original work is properly cited. 